\title{
A Smart Material Interfaces Learning Experience
}

\author{
Andrea Minuto \\ HMI Group, University of Twente \\ PO Box 217, NL-7500 AE Enschede, \\ The Netherlands \\ a.minuto@utwente.nl
}

\author{
Fabio Pittarello \\ Università Ca’ Foscari Venezia \\ Via Torino 155 \\ Venezia, Italia \\ pitt@unive.it
}

\author{
Anton Nijholt \\ HMI Group, University of Twente \\ PO Box 217, NL-7500 AE Enschede, \\ The Netherlands \\ a.nijholt@utwente.nl
}

\begin{abstract}
This paper describes a learning experience held with a class of primary school children who were introduced to a novel class of resources, named smart materials, and the interfaces built with them (Smart Material Interfaces). The pupils were guided along a multidisciplinary educational path in which traditional and innovative teaching methods were composed for educating while engaging the children. It led to the creation of 6 automated puppet plays focused on the themes of environmental awareness as a result. In this process, storytelling and visual programming acted as powerful means for merging different educational concepts and techniques. The children's engagement and the educational impact were evaluated during and after of the experience, revealing interesting results. The data collected through the direct observation and the questionnaires indicate that the experience was perceived as a positive and interesting. The post evaluation, held some months later, revealed improvements in all the areas involved by the multidisciplinary experience, from the knowledge of the properties of smart materials and the programming skills, to the increase of the environmental awareness and the skills for text analysis.
\end{abstract}

Keywords: Arduino, computer supported education, origami, smart material interface, Scratch, storytelling, visual programming.

\section{Motivation}

Educators should be able to offer up-to-date educational paths capable of integrating the novelties of science and technology with the engagement of the pupils for improved learning. Smart materials represent a novel and interesting technological topic to teach and learn. They can change their physical properties (for example color, shape, stiffness and so forth) and they can be manipulated and controlled through different hardware platforms (e.g. Arduino) for the creation of interesting and engaging interfaces (i.e. Smart Material Interfaces, SMIs). The interest of this exploratory study lays in the introduction of these complex technology topics in the Primary School and on the design of an interdisciplinary educational path supporting this goal. For reaching this goal the educational experience included scientific, technical, artistic topics and literacy skills, meant for engaging the children while educating them. It is important to underline that the topics that were introduced for stimulating the interest for the smart materials worked not just as a means but they were themselves a focus of interest. Storytelling, which has long

DOI reference number: 10.18293/DMS2015-013 been recognised as a powerful means for engaging children in educational contexts, was used in this work as a glue for connecting the different educational topics. Storytelling provided an overall goal to the students' work: the creation of stories focused on environmental awareness themes. In this experience the children were challenged in the creation of origami ${ }^{1}$ models as elements of a story. These elements were augmented with smart materials and programmed to act as the stories created by the children prescribed. A Scratch ${ }^{2}$ based environment was used as mediating tool for translating the narrative structures into programming blocks. It connected the models to an Arduino board ${ }^{3}$ for triggering the actions of the associated smart materials. The Arduino-controlled stories were finally represented in cardboard theatres.

The data collected during and after the experience indicate that the educational path was perceived as engaging and that the children improved their skills and knowledge. We collected these data during and after the experience using different means: direct observation, video recording, questionnaires and also replicating some tasks a few months after the end of the project. The engagement was positively evaluated through the analysis of various parameters [1] such as: perceived usability, felt involvement, focused attention, aesthetics, novelty and endurability. The educational impact was measured some months after the end of the pedagogical path and revealed improvements in all the areas involved by the multidisciplinary experience. In the next sections we will show an overview of related works (Sec. II), we will give an explanation of the material used (Sec. III), and the teaching process (Sec. IV). We will then describe the evaluation conduced and analyse our results (Sec. V-VIII). This will be followed by our conclusions (Sec. IX).

\section{RELATED WORKS}

There are many different ways to engage and attract the interests of younger minds. Among these ways to increase motivation, one possibility is to make the task more enjoyable. It is possible for example to use interfaces made of physical objects, often belonging to the everyday experience, instead

\footnotetext{
${ }^{1}$ The Japanese art of folding paper into shapes and figures.

${ }^{2} \mathrm{~A}$ visual programming tool http://scratch.mit.edu from MIT

${ }^{3}$ Arduino is an open hardware platform http://arduino.cc
} 
of traditional ones based on the WIMP [2] paradigm ${ }^{4}$. One of these novel interfaces is described in [3], where Sun and Han tested different kinds of input interfaces, such as: keyboards, aluminium foil pads and bananas. Even though the bananas scored as the worst in performance, they were also the best for engagement and enjoyment. Other possibilities are toys such as Makey Makey [4], that proved to be an interesting tool to create tangible interfaces with children [5]. Makey Makey allows the use of everyday (conductive) objects such as fruits to create interactive interfaces that can drive games made with Scratch. This allows the children to have fun with games, while learning and improving their personal skills. In this context of development of games for children with Scratch we need to note that other visual programming environments have contributed significantly to the field, an example is Blockly [6]. Blockly is a similar visual programming editor (usable via browser, without installation of software or plugins) that allows children to learn programming while playing. All of the above studies also tended to ask the children to make things, to produce their own object of play. As we know from [7] [8], "many studies [...] suggest that storytelling (meant as the capacity to listen, tell, and reflect on stories) is an extremely important developmental area for children, promoting a wide spectrum of cognitive functions and skills: expression, communication, recognition, recall, interpretation, analysis, and synthesis". Some experiences related to storytelling take advantage of visual programming languages. Different researchers have designed and experimented with visual paradigms for children, with the goal of teaching them to program. Alice [9], one of the most famous languages, allows children to program a $3 \mathrm{D}$ environment using a drag and drop style. Looking Glass [10], a successor, introduces children to programming by coupling $3 \mathrm{D}$ and storytelling. Scratch is a block based graphical programming language that permits children to build 2D stories and games. Jacoby and Buechley experimented with children a different approach to storytelling with new tangible technologies such as conductive ink [11]. They taught children about circuitry and conductivity with an interesting kit (StoryClip) to produce drawings that they could bring to life with their recorded speech, by enhancing traditional paper with augmented properties.

The educational project presented in this work takes advantage both of visual programming paradigms and augmented physical objects, for building an engaging storytelling experience. In our work the plain physical objects are augmented taking advantage of the properties of a new category of materials, named smart materials ${ }^{5}$. Our approach is part of a new research area focused on the exploration of new synergies between traditional materials and smart ones. A number of researchers involved in this research used just paper, in the artistic shape of origami, to engage the users. Boden et al. [12] describe a

\footnotetext{
${ }^{4}$ W.I.M.P paradigm: acronym for Windows Icons Mouse and Pointer interaction paradigm, coined by Merzouga Wilberts in 1980, developed at Xerox PARC in 1973.

${ }^{5} \mathrm{~A}$ smart material is a material that can change a physical property in a controlled way (for example color, shape and so forth).
}

system designed to support augmented play and learning for children. It uses origami and augmented reality with fiducial markers. In [13], Do and Gross try to explore the possibility of creating creative environments by using interactive spaces, and using origami as a means for teaching and learning geometry and spatial reasoning. Coehlo [14] theorised about embedding materials in the paper making process to create sensors and interactive surfaces. Others in the past have tried to couple new materials with toys, for example in [15] textile is described as a user interface for an interactive toy that responds to events by changing patterns. Smart materials gave a boost for creating interfaces for learning, teaching and most of all increasing and supporting creativity with many different techniques [16]. This new kind of interfaces making use of smart materials are also called Smart Material Interfaces ${ }^{6}$. They are already embedded in electronics and products of everyday use (e.g.: sunglasses that darken only in bright environments, glasses that remember their shape even after deformation, markers that appear when the temperature reaches a certain value i.e. liquid crystal thermometers, and so forth). But only recently have they started to be used in the creation of SMIs and in doit-yourself projects. Some of these are more expensive, others cheaper, but all of them try to interest and empower the user in making things, in participating in the creative process.

\section{MATERIALS FOR THE EXPERIENCE}

The smart materials used for this experience are of two kinds, the choice was based on the most aesthetic and interesting properties: changing shapes and colours. We used shape memory alloy (SMA) wires and thermochromic paints of various colours.

The thermochromic paint is a paint that has a thermic threshold, once this temperature limit is reached the paint becomes transparent. We applied a serpentine of resistive wire to the back of the paper to reach the necessary temperature gradient, this allowed us to "switch the color on and off" on command.

The SMAs is a big family of materials: we employed NiTiNOL. This specific kind has the property to contract once the temperature threshold is reached $\left(\right.$ Flexinol $\left.^{7}\right)$. We created several actuators with it, to be applied to the children's creations. They were made following the implementation shown in [18] but with only one degree of freedom. To control the temperature in both cases we used Arduino and a small paper board made with conductive tape with a MOSFET ${ }^{8}$ on it. Each board was used to control a single origami model and the related animations.

For the educational experience we decided to used $\mathrm{S}^{4} \mathrm{~A}^{9}$, a modified version of Scratch. S4A allows the control of actuators through the Arduino pins using the same language as Scratch. This way the children were able to program Arduino and to create animations for the smart origami models by

\footnotetext{
${ }^{6} \mathrm{SMI}$ are interfaces that can relay information in a material way [17].

${ }^{7}$ More technical information can be found at http://musclewires.com.

${ }^{8} \mathrm{~A}$ MOSFET is a specific kind of transistor.

${ }^{9}$ Realised in the context of the EU project Citilab http://seaside.citilab.eu.
} 


\begin{tabular}{|c|c|c|c|c|}
\hline Session & Lesson description & Survey & Main Focus & Length \\
\hline 1 & We taught the children how to make plain origami models and create stories with them(Sec. IV-A). & & origami & 1 half-day \\
\hline 2 & We introduced SMIs with several small examples. (Sec. IV-B). & First & SMIs & 1 half-day \\
\hline 3 & The children modified their stories for adding smart materials to origami (Sec. IV-C). & & narration, SMIs & 1 half-day \\
\hline 4 & $\begin{array}{l}\text { The children broke down their stories into narrative blocks, introducing symbols to come closer } \\
\text { to a programming language (Sec. IV-D). }\end{array}$ & & $\begin{array}{l}\text { narration, program- } \\
\text { ming blocks }\end{array}$ & 1 half-day \\
\hline 5 & $\begin{array}{l}\text { We explained the basics of programming in S4A and taught how to create origami animations on } \\
\text { Arduino from S4A. We asked the children to program their stories(Sec. IV-E). }\end{array}$ & & S4A, Arduino & 1 day \\
\hline 6 & We prepared the setup for the final cardboard theatre representations (Sec. IV-F). & & S4A, Arduino & 1 half-day \\
\hline 7 & The children saw the realisation of their work and filled in the second questionnaire (Sec. IV-G). & Second & grading & 1 half-day \\
\hline 8 & We evaluated the educational impact after the end of the experience(Sec. IV-H). & Final & evaluation & 1 day \\
\hline
\end{tabular}

TABLE I

A SHORT DESCRIPTION, TIME LINE AND FOCUS OF ATTENTION OF EACH PHASE

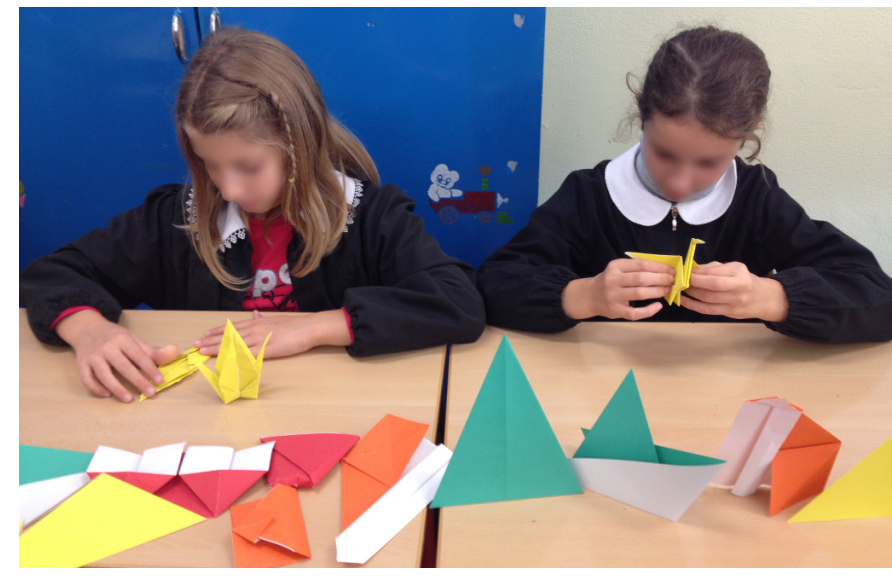

Fig. 1. Children making origami models during the first day.

themselves. For allowing the children to enter, create and record the play in the proper condition, we built three, two sided, cardboard theatres: each one is about $1 \mathrm{~m}$. wide and about $1.8 \mathrm{~m}$. tall (Fig. 2). We also made use of a smaller cardboard theatre for testing the stories.

\section{Teaching Process}

We experimented our learning path with a class of 19 Primary School children, all aged 9. None of them had any prior experience or knowledge about programming or visual programming. Some of them displayed partial knowledge about the use of the WIMP paradigm. The project was developed through 8 sessions held in the classroom and accompanied by additional homeworks. During the whole process two researchers were in the classroom, assisted by the children's teachers. Most of the sessions included collaborative phases where the children were organised in 6 groups: 5 of which composed of 3 children and one of 4 ( 3 groups of boys, 2 of girls and a mixed group), that were maintained till the end of the project. During the experience we gave 3 sets of evaluations, the first two during the experience and one after its end. In Table I we summarise the timeline of the whole experience. In preparation for the experience the teachers debated with the children about environmental behaviours.

\section{A. Session 1: How to make origami models to tell a story}

The children learned the basic techniques for making origami models. They were taught how to make simple forms representing animals and other shapes (Fig. 1). They worked individually for almost the whole session. In the same session we organised them into groups and asked them to create simple stories to be presented in a small cardboard theatre. Here the origami models created in the morning would play the part of characters. At the end we assigned the first homework. We asked each group to create a narration inspiring positive environmental behaviours. The story had to be presented with origami models, as for the first presentation. A unique theme was assigned to each group: energy consumption, light management, heating, mobility, water consumption and waste management. We also gave each group a list of positive behaviours for inspiration, coming from the activity done before the start of this experience. The week after, before starting the second session, we listened to the stories that they had created. The children presented their stories in front of their classmates, taking advantage of one of the big cardboard theatres, also used for the final representation. One of the children read the narration while the other group members moved the related origami models by hand as puppeteers.

\section{B. Session 2: Explain SMIs the easy way}

This session was dedicated to introduce the children to SMIs. The children were given explanations about the meaning of SMI and they were given practical demonstrations of origami models enhanced with smart materials. We showed them how the NiTiNOL wire could be used for generating transformations in the shape of an origami dog. We focused their attention on the fact that the wire, the origami model connected to it, could undergo transformations as a result of the activation of a battery. We experimented also the use of a proximity sensor for triggering the transformation. We then showed how the same NiTiNOL wire could be used to obtain simple rotations of another origami model, with a different connection. We showed the children examples of thermochromic paintings applied to origami representing a whale, a crane, a Christmas tree and a house. We focused the children's attention on the fact that the thermochromic inks disappeared when a battery was connected to a resistive wire 
positioned under the painted surface, as a result of the paper heating up. In some cases the activation of the battery resulted in simple chromatic effects, while in other cases it revealed hidden drawings. The activation of the smart materials was manually triggered by the researchers or by the children. After the practical demo the children had the opportunity to examine the smart materials. They experimented by heating the colours with the natural warmth of their hands.

\section{Session 3: Let's modify the stories to make them animated}

At the end of the previous session the children were given their second homework. The groups had to modify the stories they had created to take advantage of the possibilities offered by the smart materials. The idea was to animate the origami models mechanically and to create dynamic effects with the smart paint. For technical reasons, we did not allow the use of more than three smart origami models, but we gave the freedom to choose among any combination of NiTiNOL wires and thermochromic paints. The children were given a questionnaire with both closed and open questions. We used it for assessing the children's opinions after the first contact with the smart materials. A week later, we analysed the children's homework. The groups had chosen different combinations of mechanical animations and chromatic effects, sometimes modifying the narration for adapting it to the introduction of smart materials. For example a group with a story about a dog and four frogs living in a house, took advantage of smart materials for animating the most dynamic character, the dog. The children decided to use thermochromic paint for revealing the content of one of the posters written by the dog. They also added a sequence at the end of the narration where the curtains, painted in thermochromic ink, disappeared to let the sunlight in. We assisted the children in creating or modifying the existing origami models to support the edited narrations. Because of time constraints, we did not to let the children fix the resistive wire. But they applied the thermochromic paints to their paper works and we positioned the wire for them after the end of the session. At the end of the session we showed the children how the puppet plays could be triggered not only manually, but also by a software program, generating complex automated shows. We gave them a test play in the cardboard theatre of a previously written story as an example of the final result. In it, the smart origami models, that we had shown them in the previous session, acted as automated characters while a recorded narration was played (Fig. 2).

\section{Session 4: Analyse the story and split in narrative blocks}

At the end of the previous session, the groups were assigned their third homework: to analyse the story that they had created and identify its basic components. We asked them to identify with arrows the different sentences, distinguishing the parts played by the narrator and by the different characters. We asked the children to introduce or identify the audio effects that they wanted in the story by using additional arrows and to use a circular arrow with a number for identifying the repetitions (e.g., a triple barking should have been represented with the

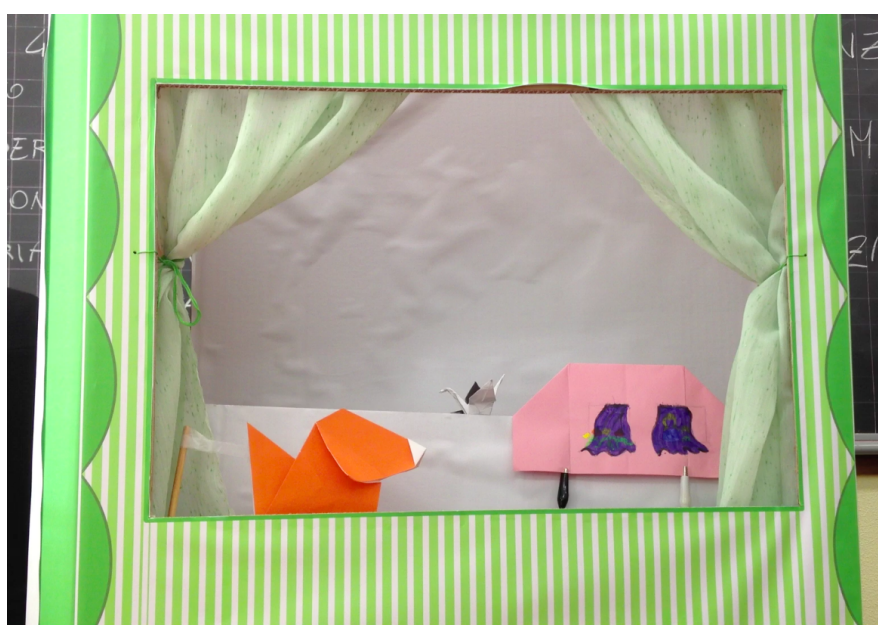

Fig. 2. The demo the researchers created to show how the smart origami models work with the story. From the left: 1) in orange, the barking dog NiTiNOL actuated 2) a small crane with thermochromic wings 3) a house with flowers hidden behind the thermochromic curtains.

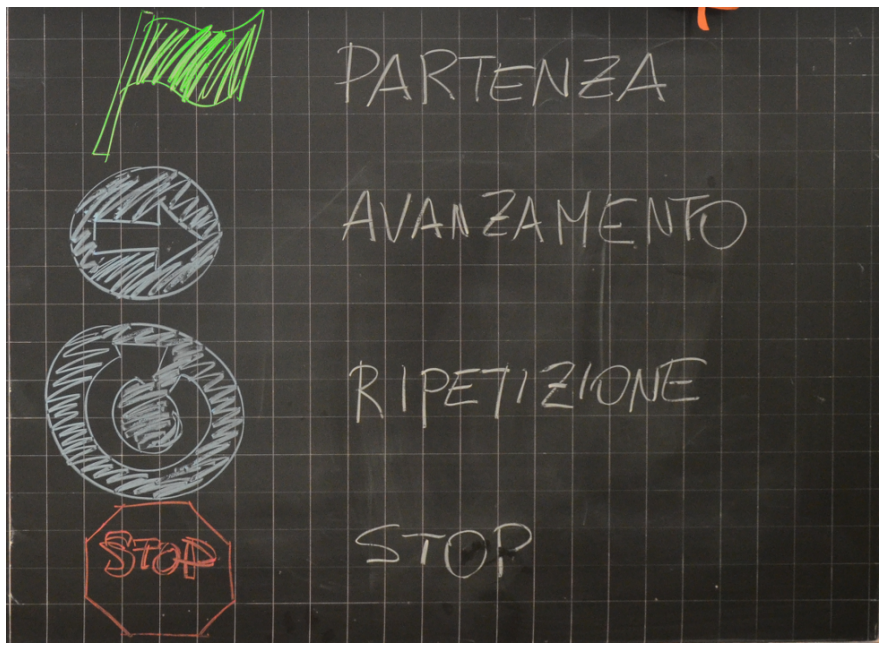

Fig. 3. Instruction marks, from the top: START, GO ON, REPEAT, STOP.

label bark preceded by the circular arrow and the number $3)$. We introduced the green flag symbol for specifying the beginning of the story and the red signal with the label stop for identifying the end of the story (Fig. 3). The children could use the same symbol, accompanied by a numerical label if they wanted to introduce pauses in the narration (e.g., a pause of 2 seconds between sentences spoken by a characters). For easing their work, we gave the them a complete analysis' example: the story text we had just played (Fig. 2) with the symbols.

\section{E. Session 5: Programming (in S4A) and record the story!}

This session lasted a whole day. During the first part, we showed the theatrical play of our story again, then we explained how everything worked. We showed how the smart origami models (SMIs) were connected to Arduino and how they could be controlled from S4A. We showed the children how the structures of our story had been translated into visual code that could be easily read and run by clicking 


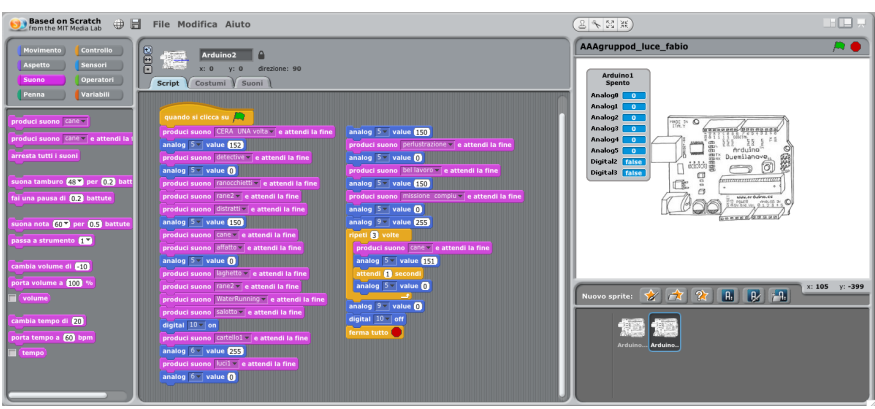

Fig. 4. A screenshot of S4A. From the left: 1) the library for changing the Arduino pins 2) a program 3) the area where the values are displayed.

a green flag placed at the beginning. We showed examples on how the narrative blocks and the other structures could be translated into visual programming entities. We focused on the programming entities that we could associate with the narrative blocks: the play sound block for playing the narration fragments and the special effects and the analog block for controlling the smart origami figures. We also showed the different control structures that we had mapped to the narration (i.e., the sequence of blocks, start and stop, repeat and wait) and parameters. After the explanation each group was supervised by a researcher while translating their stories into the programming structures with S4A. We checked the correctness of the homework. The process continued with the selection of the different blocks mapped onto narrative structures, the recording of the audio fragments of the story, the selection of the audio effects and the specification of the parameters associated to the control structures. The children tested and ran the program till they reached a satisfying result. Fig. 4 shows the visual code of the story of the dog and the four frogs. The children took advantage of all the blocks described in our tutorials: the magenta play sound and the blue analog block for animating the origami figures (i.e., the SMI connected elements). This group also introduced a lamp in their narration, so we taught them how to control it through the blue digital block. The children used the control structure for starting, pausing and ending the narration. The repeat was used to reproduce the barking sound and corresponding animation (repeated contraction and relaxation of the NiTiNOL wire).

\section{F. Session 6: Fix the scene! Proceed with animations}

After the story translations, we prepared for the final representations of the stories. We used 3, two sided, cardboard theatres. Each side was coloured for the environmental theme associated to the narration. After positioning the background scenarios created by the children, we positioned the smart origami models on the scene and connected them to Arduino and to a laptop running S4A. Because of their age, we did not involve the children in the electric connections. We realised all the process in the classroom, so that they could see how the results of their efforts would have been translated into an automated representation. Because of time constraint (the normal schooling hours of the class), we were only able to
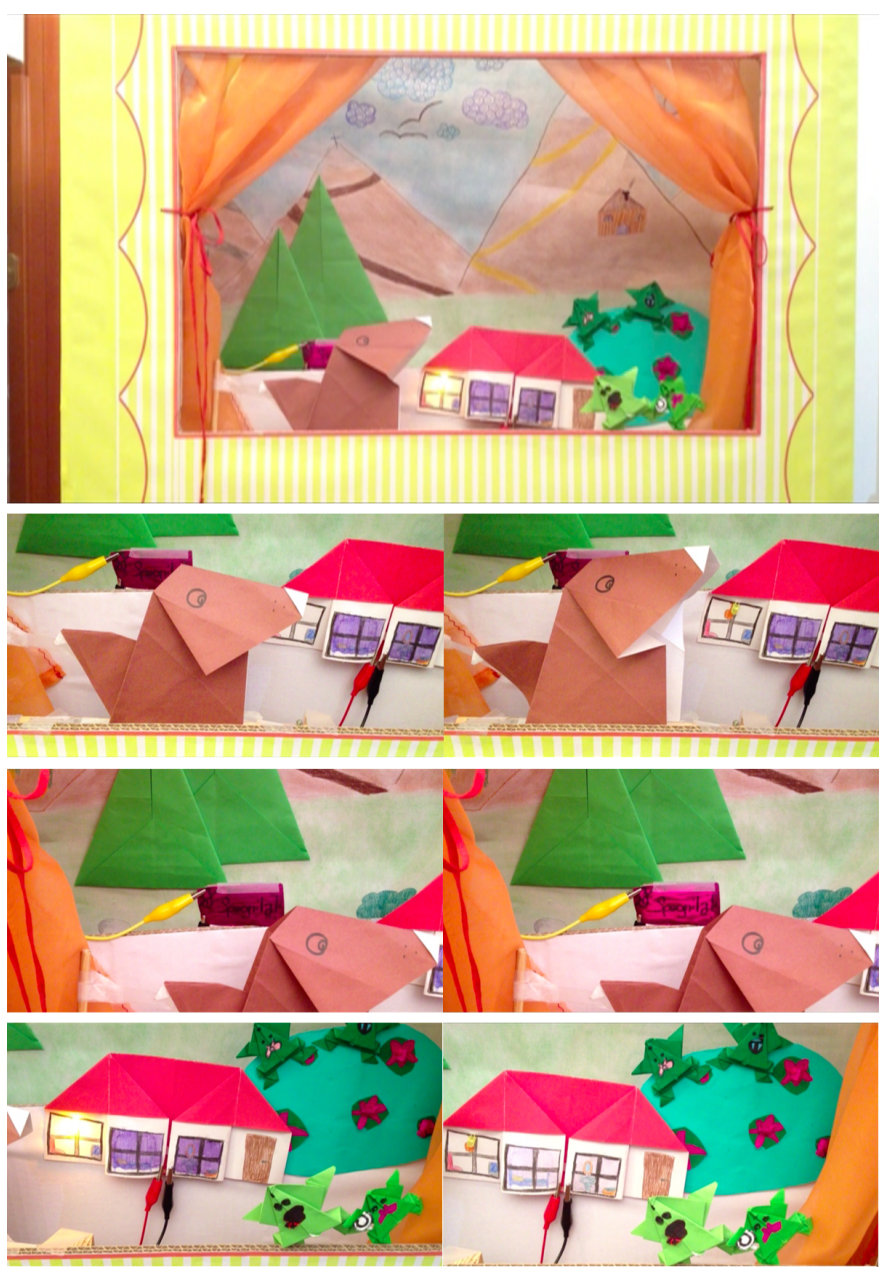

Fig. 5. The story of "the four frogs and the smart dog" living in the same house. The dog, expert on energy consumption, inspires positive behaviours and gives the frogs useful advice, exposing written posters when they forget to switch off unnecessary lights. The miniatures below the main scene represent: the animation of the dog (NiTiNOL powered), the disclosure of the word written on the poster (thermochromic paint with resistive wire), the switchable light (LED) and the curtains revealing the house's interior (thermochromic paint with resistive wire).

set up and play one of the children's stories, after which the children had to go home. This was enough to let them all see the process of building the representation, but prevented them from seeing all the final stories. After the end of the session, we assembled and recorded all the theatrical representations of the stories.

\section{G. Session 7: Watching and voting the stories}

A week later, the children watched their stories on a large screen. One of the stories (i.e., the story of the four frogs and the smart dog) can be seen in Fig. 5. It shows how the smart origami works. After each representation each child assigned a grade to the story. A questionnaire ended the session.

\section{H. Session 8: Evaluating the educational results}

After the end of the experience, months later, we returned to check its educational impact. 


\begin{tabular}{|c|c|c|c|c|c|c|}
\hline \multirow[t]{2}{*}{ Parameters and Questions } & \multirow[t]{2}{*}{ Smileyom. all (a) } & \multicolumn{5}{|c|}{ Smileyometer value per task (b) } \\
\hline & & 1 & 2 & 3 & 4 & 5 \\
\hline perceived usability: how easy was it for you to perform the project activities? & 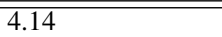 & 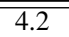 & 4.32 & 3.89 & 3.79 & 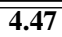 \\
\hline felt involvement: how much did you enjoy to perform the project activities? & 4.33 & 4.74 & 4.63 & 3.58 & 4.32 & 4.37 \\
\hline focused attention: how interesting was for you to perform the project activities? & 4.15 & 4.32 & 4.42 & 3.63 & 3.89 & 4.47 \\
\hline novelty: how new did you find the project activities? & 4.26 & 3.74 & 4.79 & 3.11 & 4.79 & 4.89 \\
\hline endurability: how much would you like to perform again the project activities? & 4.16 & 3.84 & 4.74 & 3.37 & 4.11 & 4.74 \\
\hline aesthetics: how much did you like the stories created by your fellows? & 3.81 jury & \multicolumn{5}{|c|}{ - not applicable - } \\
\hline
\end{tabular}

TABLE III

SECOND QUESTIONNAIRE (SEC VII) - SCORES ASSIGNED By THE CHILDREN TO THE 6 PARAMETERS THAT DEFINE THE ENGAGEMENT. COLUMN (A) REPRESENTS THE OVERALL MEAN SCORES, COLUMN (B) REPRESENTS THE MEAN OF EACH TASK (THE BEST TASK SCORE IS HIGHLIGHTED IN BOLD)

THE LIST OF THE TASKS: (1) MAKE ORIGAMI MODELS; (2) ENHANCE ORIGAMI MODELS WITH SMART PAINTINGS; (3) WRITE THE STORIES; (4) ENHANCE THE STORY WITH SMART MATERIALS; (5) TRANSFORM THE STORIES TO VISUAL PROGRAMS FOR AUTO-PLAY. FOR THE SIXTH PARAMETER (AESTHETICS) THE MEAN SCORE IN COLUMN (B) DERIVES FROM THE VOTES OF THE JURY OF CHILDREN.

\begin{tabular}{lc}
\hline Parameter & Mean \\
\hline \hline Overall interest for SMI & 2.94 \\
\hline Int. for NiTiNOL wire (for moving objects) & 2.61 \\
\hline Int. for NiTiNOL wire (for changing shapes) & 2.50 \\
\hline Int. for thermochromic ink (for changing color) & 2.67 \\
\hline Int. for thermochromic ink (for reveal. objects) & 2.89 \\
\hline \hline
\end{tabular}

TABLE II

First Questionnaire (SEC. VI) - MEAN SCORES ASSigned By THE CHILDREN USING A 3-POINTS SCALE

\section{RESUlts}

In the next sections we present all the cumulated results during and after the experience. We tracked the educational process using several methods: direct observation, videos and questionnaires. The post evaluation, held a few months after the end of the experience, also included a set of individual and group tasks to check the educational improvements. We registered high levels of interest during all the phases, in particular for those activities that were perceived as new (i.e., origami models creation, demonstration and the making of SMI, demonstration and the making of visual programs). We measured our qualitative observations with 3 evaluations, after the first SMIs demo, at the end of the experience and a post evaluation some months later.

\section{VI. $1^{\text {ST }}$ QUESTIONNAIRE: APPROACHING SMI}

After our SMIs demo (Sec. IV-B), we captured the first reaction with the first questionnaire.

Table II shows the results of a set of closed questions targeted for the interest of the children for the SMI (overall) and for the possibility of experimenting again with the different types of materials. The mean results, measured through a 3points scale $(1=$ low, $3=$ high), display high interest for the SMI and especially for the use of thermochromic inks for revealing objects. We asked the children to imagine other uses for the SMIs and about two thirds of them expressed creative ideas beyond the simple extension of the functionalities we showed. Some of the proposals were focused on artistic uses of SMI, such as clocks and color changing shoes with the owner's preference or magical pencils capable of drawing in different colours. Many children proposed stimulating creative functional uses, such as glowing materials illuminating the path at night, smart books capable of turning their pages, or even super-smart materials capable of self-replicating or doing housework.

\section{VII. $2^{\text {ND }}$ QUESTIONNAIRE: THE EXPERIENCE}

The second questionnaire (Sec. IV-G) was composed mainly of closed questions addressed to analyse different facets of the pupils' experience. We analysed the six different parameters that define the user engagement according to O'Brien et al. [1]: perceived usability, felt involvement, focused attention, aesthetics, novelty and endurability. This analysis is useful for measuring all those experiences that go beyond the working activity and whose success is also determined by parameters such as aesthetics or felt involvement. For this questionnaire we used a 5-point scale, with the Smileyometer for expressing the numeric values in a more friendly fashion. The Smileyometer [19] [20] takes advantage of pictorial representations (smileys) for eliciting children's opinions. To be sure of the children's comprehension, we distributed the questionnaire in the classroom and read the questions one by one, evidencing the focus of each one and asking the children if they had any doubt about it. Table III shows the engagement parameters, the related list of questions and the resulting mean scores. We explored the children's opinions about the different active tasks that were assigned during the activities of the project. For five of the six parameters that define the engagement, we asked the children their opinion about the following tasks:

1) make origami models;

2) enhance origami models with smart paintings;

3) write the stories;

4) enhance the story with smart materials;

5) transform the stories to visual programs for auto-play.

Column (a) shows the scores derived from the means of the different tasks, while column (b) displays the results for each task. The tasks are identified by a numerical label, referring to the numbered list that we have just described above in this section. For the aesthetics parameter, there are no analytical results for each task because we used the scores assigned by the children to each play when they saw them represented in the cardboard theatres. Column (a) displays positive results 


\begin{tabular}{lc}
\hline Block/Structure & Mean \\
\hline \hline start block & 4.53 \\
\hline play sound block & 4.21 \\
\hline analog block for activating SM & 3.95 \\
\hline wait block & 4.32 \\
\hline sequence & 4.11 \\
\hline repeat block & 4.11 \\
\hline \hline
\end{tabular}

TABLE IV

SECOND QUESTIONNAIRE (SEC. VII)- EASE OF USE OF THE VISUAL BLOCKS AND CONTROL STRUCTURES (5 POINTS SCALE SMILEYOMETER).

for all the parameters that define the concept of engagement. However, the analytic scoring emphasises that the use of smart paintings (2), the story enhancement with smart materials (4) and the transformation of stories into visual programs (5) obtained higher scores for all the parameters. The making of origami models performed well but with slightly lower values, especially for the novelty and the willingness to perform the activity again. Finally the story making activity worked as a glue for the whole experience and gained positive values but lower for what concerned the novelty and the willingness to write stories in the future. The questionnaire also included additional analytic questions about the ease of translating the stories into visual programs. The positive answers displayed in Table IV confirm the results of the direct observation of the task execution, that was performed by all the groups nearly in autonomy after the collective demo in the classroom. While the ease of use gained high scores for all the blocks and control scores, the analog block was perceived as slightly less easy to use. This is because the meaning of the analog block is not intuitive. It requires one to map the SMI connected to the board with a pin number and another numerical value, the abstract duty cycle for controlling the energy fed to the SMI. A possibility for improving the situation is to change the digital (UI) and physical (Arduino) interface to a more matching and coherent meaning for the parameter choice. For example, Blockly introduced (for example on the online gaming part) a visual way to quantify the number of degrees to choose the proper value with a piechart. A complementary approach would see the Arduino interface to match colours with the S4A interface, simplifying the comprehension of the user on which is connected where.

\section{FINAL: LEARNING EVALUATION}

After the experiment we agreed with the teachers to come back in the classroom (Sec. IV-H) to check the results of the educational experience in the middle term. We had the opportunity to come back to the school a few months after the educational experience, just before of the end of the school's year.

The evaluation was structured into 4 tasks: two questionnaires, a text analysis task and a visual programming task. We examined several facets of the experience: the awareness for environmental themes, the knowledge about smart materials, the new skills for identifying the narrative structure and translating it into visual programs.

\section{A. Tasks and goals descriptions}

Task 1. The goal of this task was to verify the impact of the children narrations, on their personal environmental awareness after the end of the experience. We asked the children to fill in a questionnaire, a set of 6 open questions. For each question the children had to describe positive behaviours related to one of the thematic areas that were explored during the experience. The questionnaire was filled in in the classroom. The children had to complete the task individually in about 30 minutes.

Task 2. The goal of this task was to understand the level of comprehension of the properties of the different materials. The closed questions (of the second questionnaire) were focused on the properties of the smart materials, met during the educational experience. In particular we asked the children to focus on the factors determining a change of state on the smart materials. The questionnaire was filled in by the children in the classroom in about 30 minutes.

Task 3. The goal of this task was to verify whether the children had acquired the skill of performing a structured text analysis. We gave them a printed short story, asking them to do the same analysis they did for the stories during the experience (Sec. IV-D), splitting the narration in blocks and identifying them with the set of symbols that they used for their stories (Fig. 3). In addition to the symbols available during the experiment, we introduced the Trigger symbol, for specifying the start of the animations. Each child completed this task individually in about 30 minutes.

Task 4. The goal in this case was to check if the children had acquired the skill of manipulating the entities of a visual programming language. For this task the groups' organisation was the same used during the experience. The children were asked to map the story blocks, from the previous task, to visual programming entities, as they did during the educational experience (Sec. IV-E). Due to practical constraints the task did not involve the real activation of smart materials. However we encouraged the children to use the proper functional blocks for activating the characters of the story. Due to time constraints we limited this task to the first paragraphs of the narration. The task was preceded by a 30 seconds recap about the categories of components available in Scratch. Because the children had worked individually in task 3, we selected only the most detailed analysis. The children then integrated it with more observations. For the execution of this task, we used a room where each group completed the task in sequence, on a laptop.

\section{B. Results}

The evaluation confirmed the positive role of the experience for teaching the children new knowledge and skills. As stated at the beginning of the section, the time for coming back to the classroom and performing a post test evaluation was determined by the availability of the teachers. The results show that even after a prolonged period of time from the end of the experience (i.e. six months) and no intermediate recap, there was a high degree of retention of the knowledge and of the skills learned during the experience. 


\begin{tabular}{lcc}
\hline Parameter & Initial quest. & Final quest. \\
\hline \hline Electricity & $24 / 0$ & $\mathbf{4 1 / 1}$ \\
\hline Heating & $4 / 21$ & $\mathbf{5 / 2 6}$ \\
\hline Light & $12 / 9$ & $\mathbf{1 6 / 1 1}$ \\
\hline Transportation & $19 / 9$ & $17 / \mathbf{1 4}$ \\
\hline Waste & $21 / 0$ & $\mathbf{2 9} / 0$ \\
\hline Water & $9 / 23$ & $\mathbf{1 9 / 2 8}$ \\
\hline \hline
\end{tabular}

TABLE V

LEARNING EVALUATION - LISTING OF POSITIVE BEHAVIOURS RELATED FOR THEMATIC AREAS. THE FIRST NUMBER SHOWS THE NUMBER OF ANSWERS RELATED TO ISSUES EVIDENCED IN THE STORIES, THE SECOND SHOWS THE NUMBER OF COMPLEMENTARY ISSUES (IN BOLD, POSITIVE INCREASE OF AWARENESS, IN cursive THE NEGATIVE).

Task 1. The results show that the creation of narrations focused on environmental issues had a positive impact on the personal awareness. Table $\mathrm{V}$ displays the number of positive personal behaviours described by the children for each environmental theme. It compares the results between the questionnaire filled in before the educational experience (Sec. IV-A) and the final post-test questionnaire. For each questionnaire and for each theme the first number displays the number of answers directly related to issues evidenced in the stories, while the second number displays the answers related to complementary issues. In most of the cases the final questionnaire reveals an improvement in the children's awareness (in bold). Only for a single theme (transportation) did the results display a modest reduction of the awareness. We think that this result might be due to the fact that the related story provided an example that was not immediately transferrable to the everyday experience (i.e., the bird flying with its own wings instead of using a jet).

Task 2. The experience with the smart materials gave good results for the acquired knowledge, especially for those where the children had the opportunity to manipulate and not just observe them. The number of correct answers (Table VI) show that the children performed well in identifying how the two smart materials (NiTiNOL wire and thermochromic ink) changed their state and in understanding which were the factors driving the changes. About NiTiNOL wires, most children correctly identified the length changes and related these changes to the electric battery use, but some of them did not remember the associated temperature shift. We might relate this failure to the fact that it was not possible to let the children touch the wires during the demonstration. About the thermochromic ink, most children correctly identified the state changes and the causes that determined them. All the children had the possibility to test directly the influence of the temperature, by touching the painted objects and verifying the effect of the warmth of their hands.

Task 3. The results displayed relevant skills for the text analysis. Table VII shows the number of symbols used for splitting each story into logical blocks, evidencing for each type mean and standard deviation. All the children placed the Start symbol correctly at the beginning of the story and the majority of them used the Go on symbols correctly to

\begin{tabular}{lc}
\hline Topics & Correct answers \\
\hline \hline Factors changing appearance in the NiTiNOL wire: & \\
\hline \hline - ambiental noise (no) & $17 / 18$ \\
\hline - wire temperature (yes) & $6 / 18$ \\
\hline - room illumination (no) & $17 / 18$ \\
\hline - electricity (yes) & $17 / 18$ \\
\hline - proximity (no) & $11 / 18$ \\
\hline \hline The NiTiNOL wire changed its appearance: & $16 / 18$ \\
\hline \hline - changing its length (yes) & $17 / 18$ \\
\hline - changing its visibility (no) & $14 / 18$ \\
\hline - changing its color (no) & $18 / 18$ \\
\hline Factors changing the thermochromic ink: & $16 / 18$ \\
\hline \hline - wind (no) & $16 / 18$ \\
\hline - ink temperature (yes) & $15 / 18$ \\
\hline - room illumination (no) & $18 / 18$ \\
\hline - electricity (yes) & $18 / 18$ \\
\hline - ambiental noise (no) & $18 / 18$ \\
\hline The thermochromic ink changed its appearance: \\
\hline \hline - detaching itself from the sheet of paper (no) \\
\hline - shrinking the underlying sheet of paper (no) \\
\hline - changing its visibility (yes) \\
\hline
\end{tabular}

TABLE VI

Learning Evaluation - Properties of SMART Materials

\begin{tabular}{lcc}
\hline Block & Mean & St. dev. \\
\hline \hline start symbol & 1.0 & 0.0 \\
\hline go on symbol & 8.3 & 4.9 \\
\hline trigger symbol & 4.9 & 2.3 \\
\hline repeat symbol & 3.1 & 0.8 \\
\hline stop symbol & 7.4 & 4.5 \\
\hline \hline
\end{tabular}

TABLE VII

LEARNING EVALUATION - STORY ANALYSIS: USE OF SYMBOLS FOR GIVING A STRUCTURE TO THE WHOLE STORY

split the text of the story into fragments. Only in 5 of the 19 the children used a very low number of Go on symbols (from 0 to 3 symbols). Most children identified the situations of the story that could be mapped to a cycle (e.g., repeated dog barks, noises and actions of animals involved in the story). The children appreciated the possibility to specify the animation of the characters with the Trigger symbol, recalling the experiments done with the smart origami. Most of them specified a high number of animations (mean 4.9, standard deviation 2.3, Table VII), related to the appearance of a character in the scene. The children also used the Stop symbol in different fashions. Some of them interpreted it as an entity that required an explicit restart and therefore placed a $G o$ on block after each use of the Stop symbol, while others considered it as a temporary stop that did not require an explicit restart. In most cases we identified a precise logic underlying the association of the symbols to the text. Only in some of the cases (4 out of 19) were symbols not placed in a coherent fashion. The majority of the children did a good job for the text analysis.

Task 4. The results show that all the groups succeeded in creating a Scratch program of similar complexity (Table VIII). Most groups did not have problems for mapping the Scratch components to the analysis. A single group, composed of 


\begin{tabular}{ccccccc}
\hline Group & time & start & play & repeat & wait & analog \\
\hline \hline electricity & 19.0 & 1 & 4 & 1 & 2 & 1 \\
\hline heating & 16.0 & 1 & 5 & 1 & 0 & 1 \\
\hline light & 14.0 & 1 & 5 & 1 & 2 & 1 \\
\hline transportation & 16.0 & 1 & 5 & 1 & 1 & 1 \\
\hline waste & 21.0 & 1 & 4 & 1 & 1 & 1 \\
\hline water & 18.0 & 1 & 4 & 1 & 0 & 1 \\
\hline \hline
\end{tabular}

TABLE VIII

LEARNING EVALUATION - TIME AND USE OF PROGRAMMING ENTITIES FOR TRANSLATING THE STORY INTO A VISUAL PROGRAM

children that did not give a detailed description of the structure in the previous task, needed additional support for improving the text analysis and the mapping work. The children had no problem in using the Scratch, even for the most sophisticated (i.e., the cycle that requires nested components), but still they needed time to adapt to the interface and mouse. They needed only simple verbal support for accomplishing complementary operational sequences, such as the creation and the use of audio tracks. All the groups succeeded in completing the visual programming activity, in 16 to 21 minutes (Table VIII).

\section{CONCLUSION}

The final evaluation demonstrated that the design of the educational experience was successful in many respects. The children acquired new knowledge in relation to new technological topics, such as the properties of smart materials, and acquired new skills for programming interfaces based on them. We noticed improvements in all the areas involved by the multidisciplinary experience, from the increase of the environmental awareness to the skills for the text analysis. At the end of the educational process the result of the children's efforts was both a working mechanism and a cultural artefact that was evaluated even for its aesthetic qualities.

The results of the direct observation and the questionnaires show that the children learned new concepts, acquired different skills and were engaged both in cognitive and emotional terms throughout the experience. The children learned new methods of expression, they were very interested in origami and visual programming, and declared their willingness to try again the different facets of the whole multidisciplinary experience. About storytelling: we had a confirmation of its positive role for educational paths. This goes beyond the simple teaching of literacy skills and their use for connecting different educational topics and techniques. Storytelling itself received a positive boost from the definition of the innovative educational path. As can be seen from the questionnaires, the children were not very interested in creating stories in the traditional fashion, but they were happy to create them with the SMIs. The fact that the stories were played on a screen instead of the physical theatre, had probably some minor influence on the evaluation, but we expect that this would be worsening the results and not improving them. The results are instead all very encouraging. We designed this path focusing on the experience of creation.

With this S4A experimentation, we followed the tradition of Logo and visual programming, but added the role of children as makers. As can be seen in Table III column (b), rightmost task (5), transforming the stories into visual programs for the play, 4 out of 5 parameters gained the maximum scores among the other tasks. The introduction of a visual programming paradigm brought the possibility of automatically controlling the materials' transformation. In this educational experience, the shift from smart materials to SMIs allowed the move from the simple knowledge to the experimental activation of these materials. It is important to underline that the tools that were introduced for stimulating the interest for the smart materials, worked not only as a means but they were a focus of interest themselves. Reciprocally, we can observe that smart materials were not only the main focus of this experiment, but also a useful means for explaining technology to children.

In conclusion, all the results and the children's responses indicate that the experience was perceived as a positive and interesting activity. This shows how innovative research topics, such as SMIs, can be integrated into a pedagogical path for primary schools, merging the traditional learning and other techniques (assisted by suitable visual programming tools and physical technologies). We believe that this kind of application should be further explored and that the experience presented can be an interesting future path to look forward to.

\section{ACKNOWLEDGMENTS}

We would like to thank all the people that supported this project: Matteo Fumagalli and Raffaella Carloni from the RAM Group of University of Twente, Lorenzo Moroni from MERLN Institute for Technology-Inspired Regenerative Medicine Maastricht University, the teachers Patrizia and Tecla Pasqualon from the primary school and a special thanks goes to Roberta Saccilotto and Giuliana Bordin. This publication was supported by a CTIT-ITC collaboration project.

\section{REFERENCES}

[1] H. L. O'Brien and E. G. Toms, "The development and evaluation of a survey to measure user engagement," J. Am. Soc. Inf. Sci. Technol., vol. 61, no. 1, pp. 50-69, Jan. 2010.

[2] M. G. Helander, T. K. Landauer, and P. V. Prabhu, Eds., Handbook of Human-Computer Interaction, 2nd ed. New York, NY, USA: Elsevier Science Inc., 1997.

[3] E. Sun and S. Han, "Fun with bananas: Novel inputs on enjoyment and task performance," in CHI '13 Extended Abstracts on Human Factors in Computing Systems. New York, NY, USA: ACM, 2013, pp. 1275-1280.

[4] B. M. Collective and D. Shaw, "Makey makey: Improvising tangible and nature-based user interfaces," in Proc. of TEI '12. New York, NY, USA: ACM, 2012, pp. 367-370.

[5] R. Davis, Y. Kafai, V. Vasudevan, and E. Lee, "The education arcade: Crafting, remixing, and playing with controllers for scratch games," in Proc. of IDC '13. New York, NY, USA: ACM, 2013, pp. 439-442.

[6] "Blockly," https://developers.google.com/blockly/, [Online; acc. July2015].

[7] A. Druin, Ed., The Design of Children's Technology. San Francisco, CA, USA: Morgan Kaufmann Publishers Inc., 1998.

[8] F. Garzotto and M. Forfori, "Fate2: Storytelling edutainment experiences in $2 \mathrm{~d}$ and $3 \mathrm{~d}$ collaborative spaces," in Proc. of IDC '06. New York, NY, USA: ACM, 2006, pp. 113-116.

[9] "Alice," http://www.alice.org, [Online; acc. May-2014].

[10] "Looking glass," http://lookingglass.wustl.edu, [Online; acc. May-2014].

[11] S. Jacoby and L. Buechley, "Drawing the electric: Storytelling with conductive ink," in Proc. of IDC '13. New York, NY, USA: ACM, 2013, pp. 265-268. 
[12] M. Bodén, A. Dekker, S. Viller, and B. Matthews, "Augmenting play and learning in the primary classroom," in Proc. of IDC '13. New York, NY, USA: ACM, 2013, pp. 228-236.

[13] E. Y.-L. Do and M. D. Gross, "Environments for creativity: A lab for making things," in Proc. of $C \& C$ '07. New York, NY, USA: ACM, 2007, pp. 27-36.

[14] M. Coelho, L. Hall, J. Berzowska, and P. Maes, "Pulp-based computing: a framework for building computers out of paper," in CHI '09 Extended Abstracts on Human Factors in Computing Systems. New York, NY, USA: ACM, 2009, pp. 3527-3528.

[15] L. Berglin, "Spookies: Combining smart materials and information technology in an interactive toy," in Proc. of IDC '05. New York, NY, USA: ACM, 2005, pp. 17-23.

[16] A. Minuto and A. Nijholt, "Smart material interfaces as a methodology for interaction: A survey of smis' state of the art and development," in Proc. of SMI'13. New York, NY, USA: ACM, 2013, pp. 1-6.

[17] A. Minuto, D. Vyas, W. Poelman, and A. Nijholt, "Smart material interfaces: A vision." in Proc. of INTETAIN 2011. Springer, 2011, pp. 57-62.

[18] A. Minuto and A. Nijholt, "Growing grass: A smart material interactive display, design and construction history," in Proc. of SMI '12. New York, NY, USA: ACM, 2012, pp. 7:1-7:5.

[19] J. Read and S. Macfarlane, "Endurability, engagement and expectations: Measuring children's fun," in Interaction Design and Children, Shaker Publishing. Shaker Publishing, 2002, pp. 1-23.

[20] J. C. Read, "Validating the fun toolkit: An instrument for measuring children's opinions of technology," Cogn. Technol. Work, vol. 10, no. 2, pp. 119-128, Mar. 2008. 